Guest Editorial, part of a Special Feature on The Conservation and Restoration of Old Growth in Frequent-fire Forests of the American West

\title{
Conserving and Restoring Old Growth in Frequent-fire Forests: Cycles of Disruption and Recovery
}

\author{
Dave Egan
}

\begin{abstract}
I provide a synthesis of the papers in the Special Issue, The Conservation and Restoration of Old Growth in Frequent-fire Forests of the American West. These papers-the product of an Old Growth Writing Workshop, held at Northern Arizona University in Flagstaff, Arizona on 18-19 April 2006represent the ideas of 25 workshop participants who argue for a new attitude toward managing old growth in the frequent-fire forests of the American West. Unlike the lush, old-growth rainforests of the Pacific Northwest, the dry, frequent-fire forests of the western United States evolved with surface fires that disturbed the system with such regularity that young trees were almost always killed. When saplings did survive, they grew beyond the harm of frequent surface fires and, ultimately, attained the characteristics that define old growth in these systems. This system worked well, producing old-growth trees in abundance, until the onset of Euro-American settlement in the mid- to late- $19^{\text {th }}$ century. The arrival of these settlers put in motion an interplay of unprecedented social, political, economic, and ecological forces (e.g., removal of Native Americans and their fire-based land management systems, overgrazing of the understory, aggressive logging, establishment of federal land management agencies, implementation of a federal fire suppression policy). These activities have culminated in 1) overly dense forested ecosystems that are now on the verge of collapse because of catastrophic fires (i.e., crown fire at the landscape level; the Rodeo-Chediski Fire) and insect outbreaks, 2) the emergence of conservation-minded environmental legislation and policy, and 3 ) greater levels of interaction between citizens, federal agencies, and fire-prone landscapes. Recognizing the tenuous ecological situation of these forests, restoration ecologists, foresters, and others have developed ways to return historic ecological processes and lower tree densities to these forests. However, their efforts are not without challenges, including working with communities and citizens, serving as a bridge between entrenched bureaucracies (i.e., federal agencies and environmental groups), balancing both ecological and economic interests, and producing new applied technologies and science-based policy to advance conservation and restoration efforts aimed at preserving and developing old growth within a healthy forest environment.
\end{abstract}

Key Words: adaptive cycle, definitions of old growth, forest management, forest policy, old-growth forests, social-ecological system

\section{INTRODUCTION}

In April 2006, 25 people participated in a 2-day workshop at Northern Arizona University in Flagstaff, Arizona. The purpose of the meeting was to discuss and debate the history and future of old growth in frequent-fire forests of the American West. The results of their interactions are the eight papers in this special issue of Ecology \& Society: The Conservation and Restoration of Old Growth in Frequent-fire Forests of the American West. In these papers, the authors examine the ecological, social, and political histories that have shaped these forest ecosystems; predict how these systems will react to future conditions; and suggest means of restoring these systems so as to preserve and develop their old-growth features. Collectively, they make a case for taking a new look at managing for old growth-one that recognizes the regional and climatic differences in forest ecosystems and the effects those variations have on disturbance processes, such as surface fire, and, consequently, 
on forest structure and composition; one that understands that, in many dry western forests, catastrophic crown fire, not logging, is now the greatest threat to old growth; one that appreciates the need for a tempered, but active, hands-on management approach; and one that recognizes that we may have the technical means to make a difference in the forests, but we must do a better job of educating and social marketing to change peoples' behaviors.

In order to provide a synthesis of the papers in this special issue, I will use the adaptive cycle model of Holling and Gunderson (2002) as a guide to examine the following points:

1. Defining old growth.

2. Social practices and policy changes.

3. Technical challenges.

\section{DEFINING OLD GROWTH}

The authors of these papers tread lightly when it comes to defining old growth, and for good reason. Although simple impressions of old-growth forests as large trees in an undisturbed forest may exist in the public's mind, the truth of the matter is that answering the question, "What is an old-growth forest?" is much more complex. One thing that all the authors agree on is that, in these frequent-fire forests, old growth does not mean trees or stands or patches or landscapes that were without natural disturbances.

In their paper, Merrill Kaufmann and his colleagues provide definitions of old growth from several sources, including international ones, but ultimately conclude that the differences within the different frequent-fire forests of the western United States "attest to the complexity of describing or defining old growth in frequent-fire forests of the western United States." Nevertheless, they do provide a list of essential structural features of old growth in frequent-fire forests in Table 1 of their paper. Dan Binkley and his colleagues provide a pictorial version of old-growth features in Figure 1 of their paper, and Carl Fiedler and his co-authors provide a list of minimum stand structural requirements for old-growth ponderosa pine. It seems fair to say that these authors, although recognizing that any definition of old growth will have to be flexible because we are working with complex ecosystems, suggest that old growth in frequent-fire forested systems has the following characteristics:

- Old, but not always large trees.

- Modest amounts of large, woody debris (either standing snags or downed logs).

- Low tree density and grassy openings.

- Slightly interlocking canopies.

- Clumpy to random tree distribution.

- High levels of understory biomass and diversity.

- Slow nutrient cycling.

- Low levels of tree regeneration.

- Patchiness at the landscape level.

Seen through the lens of an adaptive cycle, these forests in their pre-European settlement state might be defined as having a high level of connectedness among the controlling variables, which were trees at the slowest level; understory biomass and surface fire, along with small-scale insect outbreaks, at the intermediate level; and, in more moist systems, stand-replacing fire and extensive insect outbreaks at the fast level. These systems also had relatively low levels of potential because frequent fire consumed much of the system biomass, leaving and encouraging what biomass that did accumulate to do so in the slowest variable-older, larger trees. Finally, the resilience of these systems tended to be high because the regularity of low-severity surface fires and the evolutionary physiological adaptations of the trees to fire (e.g., thick bark, elevated branches) combined to leave the ecosystem's legacy material (remember connection) intact and operational, forestalling any collapse of the system.

As many of the authors note (especially Scott Abella and his colleagues), today's frequent-fire forests are dramatically different systems. Instead of being resilient, healthy, and dynamic, today's systems are rigid and homogeneous (Duncan 2003), with levels of high potential (e.g., too much resource (biomass) 
accumulated in small-diameter trees), which makes them especially vulnerable to disturbances, even the low-severity fires that once were an integral process within the system. Crown fires and extensive insect outbreaks, which can now happen relatively easily in these overstocked systems (e.g., the RodeoChediski Fire and the numerous other wildfires that now occur annually throughout the western United States), overwhelm the legacy/remember connection of the adaptive cycle, destroy old growth, and make conservation and restoration of old growth more difficult and more unlikely.

\section{SOCIAL PRACTICES AND POLICY CHANGES}

As the papers by Sandra Murphy and her colleagues, Victoria Yazzie, and Diane Vosick and her coauthors point out, the frequent-fire ecosystems of the American West, and the limited old growth they contain, exist in social-ecological systems (SES; Walker et al. 2002). As such, these SES each have a history of decisions at various levels (national vs. local, institutional vs. personal) that have affected them from the very moment that humans first came to populate these ecosystems. Both Murphy and her co-authors and Yazzie focus on this history-the former with a largely Euro-American perspective, whereas Yazzie's outlook is decidedly Native American. Both of these histories point out the social practices that helped make and sustain (Native American land management practices), and then undermine (logging, overgrazing, fire suppression) the well-being of old growth in the frequent-fire forests of the American West. They also describe the adaptive measures that were taken at different points in time to "correct" problems in the systems (e.g., utilitarianism, Progressive Era reliance on experts, judicial decisions about Indian property rights, environmentalism, Land Ethic, New Forestry). Each of these papers could have outlined as management eras that illustrate adaptive cycles, much as Lance Gunderson and his colleagues did in their discussion of Florida's Everglades (Gunderson et al. 2002, Fig. 12-1), or as an historical narrative (Cronon 1992) or an historical ecology (Crumley and Marquardt 1987).

Vosick and her colleagues describe and analyze oldgrowth protection policies and legislation in the United States since the $1960 \mathrm{~s}$, and provide alternative goals and objectives to today's public perceptions of old growth, federal land management policies, and a culture of bureaucracy. Their analysis suggests that the current system is floundering in a rigidity trap (Holling et al. 2002), i.e., within a system that has high potential, high connectedness, and high resilience. In this situation, federal policymakers, federal agency bureaucrats and other personnel, and litigious environmental groups are locked into a system that focuses on single-species protection and expends excessive energies preparing or defending appeals and lawsuits. In such an arrangement of fear and mistrust, there is little room for innovation or constructive dialogue, and little chance for passing new legislation to correct problems unless it is spurred by a crisis situation that resets the adaptive cycle (e.g., the Healthy Forest Restoration Act of 2003). These authors suggest that "a necessary approach to build confidence in management decisions will be to bring stakeholders into management discussions through collaboration." Instances where a collaborative approach has been implemented (e.g., the White Mountains Stewardship Contract, and various smaller collaboration projects in New Mexico) have resulted in moving past the rigidity of the typical federal agency/environmentalist interaction, allowing citizens on all sides to interact to solve common problems (Abrams and Burns, in press; Moote et al., in press). This type of social marketing (i.e., asking a group of people to change their behavior in return for something they value; Social Marketing Institute 2007) may be the way to move people beyond awareness of their socialecological problems and give them a format for taking voluntary actions that produce both individual and community benefits.

Vosick and her counterparts also emphasize the need to move restoration efforts beyond the wildland-urban interface into outlying regions, including designated wilderness and backcountry areas. Such a shift will require a change in emphasis and strategy, and will undoubtedly raise questions about active work in areas that are otherwise passively managed.

\section{TECHNICAL CHALLENGES}

As Vosick and her colleagues point out, the timber industry either no longer exists or is a state of transition in many areas where frequent-fire forests occur in the American West. Adaptation, new technologies, and entrepreneurial innovation are now needed to move beyond a reliance on large, old 
trees as a source of income and profit. When using timber from public lands, today's wood products industry must increasingly rely on the byproducts of restoration efforts, namely small-diameter trees along with some larger-diameter thinnings. The use of smaller-diameter material means marketing and producing products, such as pellets for woodburning stoves, other biomass-based energy products, oriented-strand board and mulches, that were not part of the industry a decade ago. In the forests, as Fielder and his colleagues describe, new techniques for harvesting and felling in and around old growth are required in order to ensure that not only will old growth be preserved, but that remaining trees can develop into old growth.

The variables that may promote these transitions, both in the forest and the factory, occur at many different scales and speeds (e.g., international, national, and regional wood products markets; agency and private training of foresters and loggers; diameter cap regulations; government support and subsidies; local and regional collaboration; rising costs of energy), and make it difficult to predict whether a sustainable course of action will emerge. It may be that we have the technical means to make a difference in the forests, but that we must do a better job of educating and social marketing to change peoples' behaviors-a slower, more voluntary approach. It may be that some crisis (e. g., energy needs) will be needed to move the system into another state-a faster, but more difficult scenario. Or it may be that some combination of both will be the future.

\section{CONCLUSION}

The future of frequent-fire forests in the American West remains uncertain, but the papers presented in this special issue collectively suggest an alternative path toward making them more ecologically sustainable. We know that, globally, more and more fire-dependent ecosystems are degraded or very degraded, with fire behaving much differently than it did in the past (Shlisky et al. 2007). This study of frequent-fire forests in the western United States may then serve as an example of what happens when we allow the resilience of such ecosystems to disintegrate, and what it will take within an SES to help put them, and the human communities that interact with them, back on course.
Responses to this article can be read online at:

http://www.ecologyandsociety.org/voll2/iss2/art23/responses/

\section{LITERATURE CITED}

Abrams, J., and S. Burns. In press. Case study of community stewardship success: the White Mountain Stewardship Contract. Ecological Restoration Institute White Paper. Ecological Restoration Institute, Flagstaff, Arizona, USA.

Cronon, W. 1992. Nature's metropolis: Chicago and the Great West. W. W. Norton and Co., New York, New York, USA.

Crumley, C. L., and W. H. Marquardt, editors. 1987. Regional dynamics: Burgundian landscapes in historical perspective. Academic Press, San Diego, California, USA.

Duncan, S. 2003. The trouble with connectedness: disturbance and ecosystem crashes. Science Findings 54. U.S. Forest Service, Pacific Northwest Research Station, Portland, Oregon, USA.

Gunderson, L. H., C. S. Holling, and G. D. Peterson. 2002. Pages 315-332 in L. H. Gunderson and C. S. Holling, editors. Panarchy: understanding transformations in human and natural systems. Island Press, Washington, D.C., USA.

Holling, C. S., and L. H. Gunderson. 2002. Resilience and adaptive cycles. Pages 25-62 in L. H. Gunderson and C. S. Holling, editors. Panarchy: understanding transformations in human and natural systems. Island Press, Washington, D.C., USA.

Holling, C. S., L. H. Gunderson, and G. D. Peterson. 2002. Sustainability and panarchies. Pages 63-102 in L. H. Gunderson and C. S. Holling, editors. Panarchy: understanding transformations in human and natural systems. Island Press, Washington, D.C., USA.

Moote, A., J. Abrams, E. Krasilovsky, M. Schumann, M. Savage, and T. Derr. In press. Navigating the motives and mandates of multiparty monitoring. Ecological Restoration Institute White Paper. Ecological Restoration Institute, Flagstaff, Arizona, USA. 
Shlisky, A., J. Waugh, P. Gonzalez, M. Gonzalez, M. Manta, H. Santosa, E. Alvarado, A. A. Nuruddin, D. A. Rodríguez-Trejo, R. Swaty, D. Schmidt, M. Kaufmann, R. Myers, A. Alenar, F. Kearns, D. Johnson, J. Smith, D. Zollner, and W. Fulks. 2007. Fire, ecosystems and people: threats and strategies for global biodiversity conservation. The Nature Conservancy Global Fire Initiative, Tallahassee, Forida, USA. [online] URL: http://ww w.nature.org/initiatives/fire/science/.

Social Marketing Institute. 2007. Social marketing. Social Marketing Institute, Washington, D.C., USA. [online] URL: http://www.social-mark eting.org/sm.html.

Walker, B., S. Carpenter, J. Anderies, N. Abel, G. S. Cumming, M. Janssen, L. Lebel, J. Norberg, G.D.Peterson, and R. Pritchard. 2002. Resilience management in social-ecological systems: a working hypothesis for a participatory approach. Conservation Ecology 6(1):14. [online] URL: http: //www.consecol.org/vol6/iss1/art14/. 